EGU2020-13645

https://doi.org/10.5194/egusphere-egu2020-13645

EGU General Assembly 2020

(c) Author(s) 2020. This work is distributed under

the Creative Commons Attribution 4.0 License.

\title{
Ground penetrating radar investigations in Quebrada Montes, Lobitos, Peru
}

Lai Bun Lok ${ }^{1}$, Diego Almendrades ${ }^{2}$, Michael Alderson², Alejandro Pizarro² ${ }^{2}$ Andres Bustamante², and John $\mathrm{Shi}^{3}$

'Lancaster University, Engineering, United Kingdom of Great Britain and Northern Ireland (I.lok@lancaster.ac.uk)

${ }^{2}$ EcoSwell Peru, Lobitos, Peru

${ }^{3}$ University of Glasgow, School of Multidisciplinary Studies, Glasgow, UK

The dry equatorial forests in the north-western coast of Peru suffer from acute water stress and man-driven deforestation. Recent estimates indicate that the forests have reduced to approximately $10 \%$ of their original size. There are local reforestation efforts currently underway, for example to prevent the extinction of native species such as the Peruvian Plantcutter songbird (Phytotoma raimondii). However, irrigation needed to support such efforts is severely challenged by the issues of water scarcity in the region. These adverse effects are also being experienced at a local level by the nearby rural community in Lobitos.

The groundwater resources in Lobitos could potentially offer a solution to the above issues for the local community. However, a scientifically informed and sustainable method of mapping and utilising this resource is needed. To provide supporting evidence in this effort, an extensive ground penetrating radar survey was conducted using a commercial $80 \mathrm{MHz}$ impulse radar to characterise the near subsurface within a 90 hectare plot called Ecológica Tallán, which is part of a natural dry water channel in Quebrada Montes and declared as an important conservation area for the district.

Through a pilot study between Lancaster University, EcoSwell Peru and University of Glasgow, we report on initial results from our ground penetrating radar survey to provide a better understanding of the subsurface characteristics in Quebrada Montes, Lobitos. 